Article

\title{
Validating salinity from SMAP with saildrones and research vessel data during EUREC ${ }^{4}$ A-OA/ATOMIC
}

\author{
Kashawn Hall ${ }^{1 *}$, Alton Daley ${ }^{2}$, Shanice Whitehall ${ }^{3}$, Sanola Sandiford ${ }^{4}$, Chelle L. Gentemann ${ }^{5}$ \\ 1 Caribbean Institute for Meteorology and Hydrology; khall@cimh.edu.bb \\ 2 Caribbean Institute for Meteorology and Hydrology; adaley@cimh.edu.bb \\ 3 Caribbean Institute for Meteorology and Hydrology; swhitehall@cimh.edu.bb \\ 4 Caribbean Institute for Meteorology and Hydrology; ssandiford@cimh.edu.bb \\ 5 Farallon Institute; cgentemann@faralloninstitute.org \\ * Correspondence: khall@cimh.edu.bb; Tel.: 1246-547-7283
}

\begin{abstract}
The 2020 Elucidating the role of clouds-circulation coupling in climate - Ocean-Atmosphere (EUREC $\left.{ }^{4} \mathrm{~A}-\mathrm{OA}\right)$ and Atlantic Tradewind Ocean-Atmosphere Mesoscale Interaction Campaign (ATOMIC) campaigns sought to improve the knowledge of the interaction between clouds, convection and circulation and their function in our changing climate. The campaign consisted of numerous research technologies, some of which are relatively novel to the scientific community. In this study we used a saildrone uncrewed surface vehicle to validate satellite and modelled sea surface salinity (SSS) products in the Western Tropical Atlantic. These products include the Soil Moisture Active Passive (SMAP) Jet Propulsion Laboratory (JPL), SMAP Remote Sensing Systems (RSS), and Hybrid Coordinate Ocean Model (HYCOM). In addition to the validation, we investigated a fresh tongue south east of Barbados. The saildrones accurately depicted the salinity conditions and all satellite and modelled products performed well in areas that lacked small-scale salinity variability. However, SMAP RSS $70 \mathrm{~km}$ outperformed its counterparts in areas with small submesoscale irregularities while RSS $40 \mathrm{~km}$ was better at identifying small irregularities in salinity such as a fresh tongue. These results will allow researchers to make informed decisions regarding the most ideal product for their application and aid in the improvement of mesoscale and submesoscale SSS products, which can lead to the refinement of numerical weather prediction (NWP) and climate models.
\end{abstract}

Keywords: Saildrone, Soil Moisture Active Passive (SMAP); Hybrid Coordinate Ocean Model (HYCOM); EUREC4A; ATOMIC; physical oceanography; remote sensing; air-sea interactions

\section{Introduction}

Three saildrone vehicles collected data during a 45-day cruise from Bridgetown, Barbados, participating in the international field campaign: Elucidating the role of cloudscirculation coupling in climate - Ocean-Atmosphere component (EUREC $\left.{ }^{4} \mathrm{~A}-\mathrm{OA}\right)$ and the Atlantic Tradewind Ocean-Atmosphere Mesoscale Interaction Campaign (ATOMIC, US). This campaign was focused on two regions East of Barbados, the North Equatorial Current and the North Brazil Current (NBC) rings (Figure 1). In the NBC ring region, known as the Boulevard des Tourbillons, observations focused on mesoscale eddies and submesoscale fronts, to improve our understanding of how ocean variability impacts atmospheric organization. In this region, the North Brazil Current advects water Northwards along the South American coast. The Amazon River outflow mixes with this water to create cooler, fresher, waters that move Northward, break off into rings and eddies, which continue Northwards towards the Caribbean. These eddies form a component of the Atlantic Meridional Overturning Circulation (AMOC) and can modify local air-sea interactions and boundary layer structure [1,2]. The saildrones provided air-sea interface observations for this research and salinity information for validation of NASA SMAP salinity. 


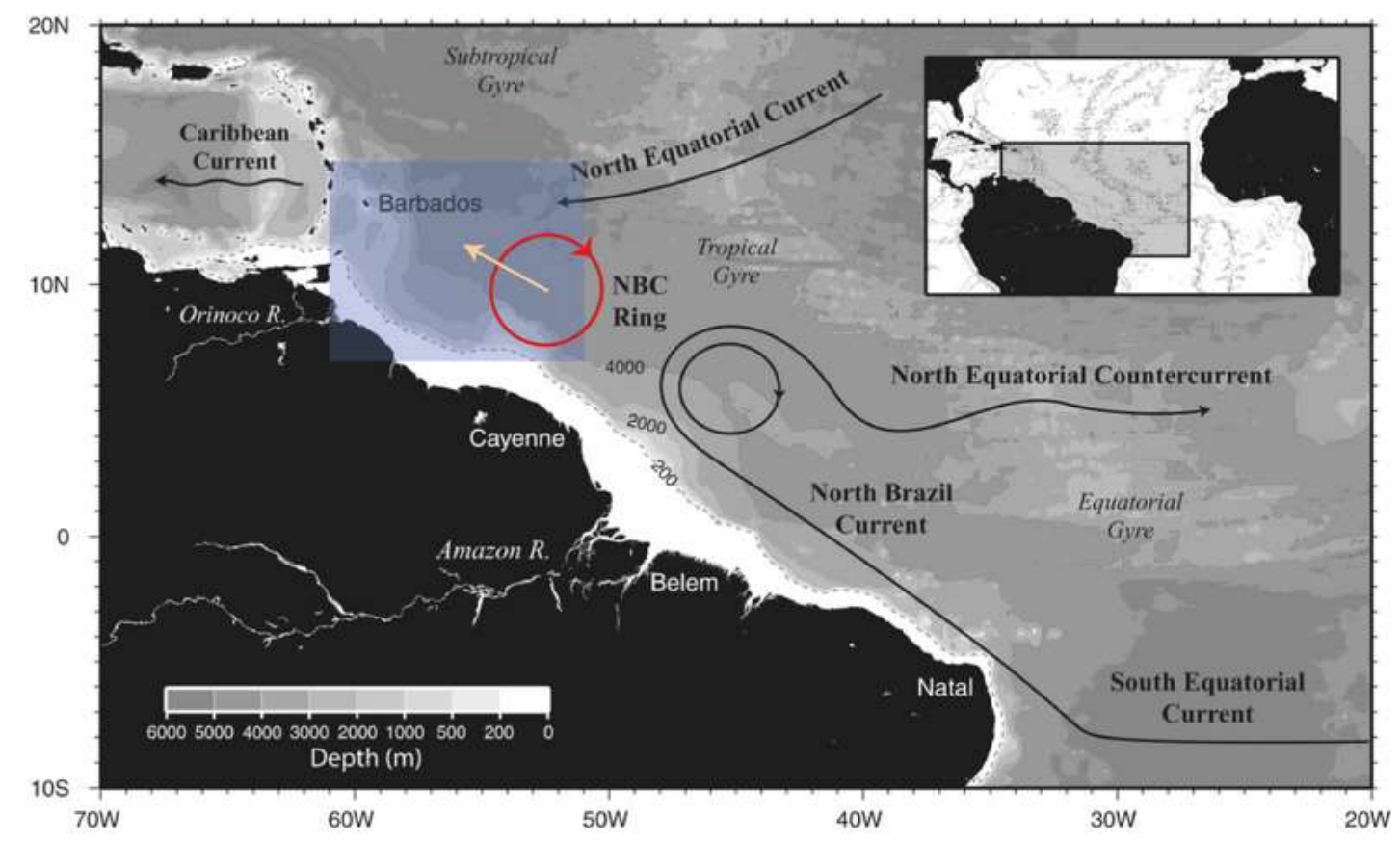

Figure 1. The region of EUREC ${ }^{4} \mathrm{~A}-\mathrm{OA} / \mathrm{ATOMIC}$ study. Saildrones will focus on the region with submesoscale variability known as the Boulevard des Tourbillions where the NBC rings can result in strong fronts and ocean barrier layers. Adapted from [3] by [4].

Observations of ocean salinity and density can provide information regarding overall ocean dynamics especially in areas with complex ocean dynamics such as the Boulevard des Tourbillons [5-7]. Salinity variations provide insight into the oceanic circulation and air sea fluxes which in turn impact the atmospheric boundary layer and make determinations on changes in the earth's climate [8]. Salinity is also used for monitoring the movements of water masses along with vertical exchange of water between surface and subsurface layers [9]. Therefore, it is imperative that SSS data collected are of the highest quality. Historically, in situ measurements of salinity and temperature were taken from ships using bucket and thermosalinograph (TSG) measurements and were poorly recorded on a global scale [10]. However, this changed at the start of the 21st century with the implementation of the Argo float programme, which allowed for global observations of salinity [5]. This global network, consisting of several autonomous Argo profilers, produces $3^{\circ}$ spatial resolution salinity data at 10 day intervals, but these spatial and temporal resolutions are too coarse to provide useful salinity observations at the mesoscale level [11]. Global satellite ocean salinity measurements were not obtained until the Aquarius mission of 2011 to 2015, which had a spatial resolution of $1^{\circ}$ and a 7-day repeat cycle [12]. This was followed by instruments such as NASA's Soil Moisture Active Passive (SMAP) which has a resolution of $40 \mathrm{~km}$ and a repeat cycle of 8-days [13]. Although satellite use greatly improved the acquisition of salinity data, there are still inaccuracies when making measurements near to the coast as well as in high latitude oceans with low sea surface temperatures. Both of these are due to limitations of the L-band microwave radiometers used by satellites to make these measurements [14]. Contemporary in situ observations done by the saildrone eliminate the limitations of satellite derived salinity and traditional in situ data. This technology is capable of resolving mesoscale and submesoscale variability observed in coastal regions [15].

Understanding ocean-atmosphere interactions in the Western Tropical Atlantic is vital in order to develop new parameterizations for numerical weather prediction (NWP) and climate models. Small Island Developing States (SIDs) of the Caribbean which lie in this portion of the Atlantic heavily rely on NWP. SIDs are extremely vulnerable to weather and climate extremes and salinity plays an important role in many of these weather and 
climate patterns. Studies have shown that salinity stratification as a result of riverine outflow by the Amazon reduces SST cooling during hurricane passage supporting hurricane intensification [16,17]. This freshwater influx is also important to El Niño Southern Oscillation (ENSO) predictability. The EUREC ${ }^{4} \mathrm{~A}-\mathrm{OA} / \mathrm{ATOMIC}$ campaign resulted in an unmatched observing effort in the western tropical Atlantic and saildrone observations during the campaign are presented in this study and will be used to validate three SMAP satellite salinity datasets and the Hybrid Coordinate Ocean Model (HYCOM). This validation will assess how well these platforms are measuring and predicting salinity and strong salinity gradients, like those present in the NBC region.

\section{Materials and Methods}

\subsection{Saildrone}

Saildrones are zero-emission, wind propelled vehicles with solar panels providing power for science-grade instrumentation. They have 12 sensors to measure data at the airsea interface (eg. SST, air temperature, 3D winds) and can carry 1 additional sensor on the keel (acoustic Doppler current profilers (ADCP), scientific echo-sounders for biomass assessment and bathymetry surveys, or a passive acoustic recorder for marine mammal studies). A Global Positioning System (GPS) and an onboard computer, enables the vehicles to navigate following prescribed waypoints, while staying within a set corridor, taking winds and currents into consideration autonomously. Waypoints can be dynamically updated by scientists as environmental conditions change or interesting features develop. Vehicles are controlled and data is returned in near-real-time via two-way Iridium satellite communications. Saildrones are able to travel approximately $100 \mathrm{~km}$ per day, depending on wind speed, and can operate in remote regions where research vessels may be time and cost prohibitive.

During the EUREC ${ }^{4} \mathrm{~A}-\mathrm{OA} / \mathrm{ATOMIC}$ cruise, each saildrone vehicle carried a full suite of instruments, including an ADCP, and an additional four RBR temperature loggers arranged along it's keel to monitor upper ocean temperature stratification. Salinity, temperature, and dissolved oxygen were measured by both a SeaBird-37-SMP-ODO Microcat and RBR CTD/ODO/Chl-A for 12 seconds, centered and averaged at each minute. Each saildrone cruise involves different instruments, but the calibration methodology is consistent from cruise to cruise.

Evaluating the accuracy of data from the saildrones is of great importance because Saildrone Inc.'s core strategy is unconventional. Previously, scientists would acquire their equipment and the task of maintenance, calibration, and deployment would be their responsibility [18]. However, in this case, saildrone is responsible for all activities about the equipment onboard the drones; scientists only purchase the data from Saildrone Inc. Additionally, unexpected issues may arise with some instruments because of the structure of the vehicle [18]. Sensors onboard the saildrone vehicle are calibrated by the manufacturers. In some cases, recalibration is performed depending on how long the device was at the manufacturer's facility after the first calibration. Gentemann [18] also points out that recalibration of some sensors is also carried out by the International Organization for Standardization/International Electrotechnical Commission (ISO/IEC) 17205 accredited calibration labs.

Preceding the EUREC ${ }^{4} \mathrm{~A}-\mathrm{OA} / \mathrm{ATOMIC}$ campaign, the saildrones were deployed in research field campaigns, scientific missions, and cruises including the Innovative Technology for Arctic Exploration (ITAE), Salinity Process in the Upper-ocean Regional Study 2 (SPURS-2) in the Tropical Pacific, and the Baja cruise from the San Francisco Bay, down the U.S. and Mexican coast to Guadalupe Island. Data collected by saildrones involved in the ITAE cruise, from 1-10 May were validated against those collected by sensors onboard the NOAA research vessel Oscar Dyson for periods when both vessels were collocated [19]. The results reveal that the root mean square (RMS) difference for the wind speed, wind direction, and the air temperature was $0.62 \mathrm{~ms}^{-1}, 3.8^{\circ}$, and $0.10{ }^{\circ} \mathrm{C}$, respectively. Sea 
surface salinity (SSS) for the saildrones had an RMS difference of 0.01 practical salinity unit (psu), and the RMS difference for sea surface temperature was $0.042{ }^{\circ} \mathrm{C}$. The SPURS2 campaign was executed from 18 October to 6 November. Data collected by the saildrones during this campaign were validated against the Woods Hole Oceanographic Institute (WHOI) buoy located at $10^{\circ} \mathrm{N}$ and $125^{\circ} \mathrm{W}$ in the Tropical Pacific [20]. The buoy carries the Air-Sea Interaction Meteorology System (ASIMET), making it an ideal benchmark for validating the saildrone sensors. The analysis revealed that the RMS difference in wind speed, wind direction, and the air temperature was $0.63 \mathrm{~ms}^{-1}, 16.0^{\circ}$, and $0.31{ }^{\circ} \mathrm{C}$, respectively. The RMS differences observed for SSS and SST were $0.047^{\circ} \mathrm{C}$ and $0.075 \mathrm{psu}$, respectively. Both the wind speed and wind direction RMS differences observed in the SPURS2 campaign were higher than expected. In the case of the wind speed, Zhang [20] attributes this high value to the flow distortion around both platforms. The flow distortion has a marginal effect on the saildrones and a substantial effect on the buoy. Additionally, Zhang [20] reveals that despite the high nature of the RMS difference in wind direction, the values fall within the limits of the local variability, making them sufficient to resolve wind direction in this area.

The most recent validation of the saildrone data took place during the Baja Cruise from the 11 April to 11 June 2018. The saildrone data was validated against data from moored buoys off the coast of California [18]. Before, the validation data from the saildrones were averaged due to the difference in sampling rates for both platforms. The 1min data for the winds were converted to $10 \mathrm{~min}$, and for the remaining data, an 8-min average for the last 8-min in an hour was computed. According to Gentemann et al. [18], the biases and standard deviations observed for the SST, air temperature, wind speed, and direction agreed well with those obtained from other in situ observation platforms. Gentemann et. al [18], also highlights an increase in variability of wind direction accuracy for values below $3 \mathrm{~ms}^{-1}$, when data from the saildrone's sonic anemometer was compared to the four-blade, impeller-driven, wind vane sensors from the buoy. This variability seems to dominate in the vicinity of buoy 46086, which the saildrone only circumnavigated for less than a day, which provides a small sample size. This phenomenon is not synonymous with this campaign as Gilhousen [21] and Bowen [22] found similar results. Bowen [22] suggests that this variability may be due to the wind vane response not being as effective at low wind speeds.

The saildrone dataset presented in this study comprises surface observation data files for each of the three NASA-funded saildrones deployed. The surface data files contain saildrone platform telemetry and near-surface observational data (air temperature, sea surface skin and bulk temperatures, salinity, oxygen and chlorophyll-a concentrations, barometric pressure, wind speed and direction) for the duration of the entire cruise at 1minute temporal resolution. All data files are in netCDF format and CF/ACDD compliant, consistent with the NOAA/NCEI specification and are available from https://podaac.jpl.nasa.gov/dataset/SAILDRONE_ATOMIC.

\subsection{The Soil Moisture Active Passive (SMAP)}

The Soil Moisture Active Passive (SMAP) mission is a polar orbiting, remote sensing observatory developed by the National Aeronautics and Space Administration (NASA) for soil moisture mapping. SMAP uses an L- band radar and radiometer with a central frequencies of $1.26 \mathrm{GHz}$ and $1.41 \mathrm{GHz}$ respectively; these instruments share a 6-m deployable reflector antenna which rotates at 13 - $14.6 \mathrm{rpm}$, providing high spatial resolution with a $1000 \mathrm{~km}$ swath. Global coverage is available every 2-3 days (2 days at the poles, 3 days at the equator) with an 8-day repeat cycle. Orbit is near polar at an altitude of 685 $\mathrm{km}$ and an inclination angle of $98^{\circ}$. It is sun-synchronous, with the Local Time of Ascending Node (LTAN) at 6 PM and a 6AM descending local overpass time. The satellite was launched in January 2015 and began operation in April 2015. SMAP has been in extended operation since the completion of its prime mission phases in 2018 and has been approved to operate in this phase through 2023. Though SMAP primarily detects soil moisture it 
also detects SSS due to the L- band microwave sensitivity to salinity. SMAP data is processed by the NASA Jet Propulsion Laboratory (JPL) and the Remote Sensing System (RSS).

This paper evaluates SMAP JPL and SMAP RSS with the data collected during the 45-day EUREC ${ }^{4}$ A-OA/ATOMIC cruise. The analysis uses SMAP JPL version 5, level 2 data at a spatial resolution of $60 \mathrm{~km}$ from 17 January to 2 March 2020 and SMAP RSS version 4, level 2 at 2 spatial resolutions: $40 \mathrm{~km}$, hereafter referred to as RSS40 and $70 \mathrm{~km}$ hereafter referred to as RSS70 for the same time period. Both datasets have 8-day running means and are collocated with the in situ observations of the saildrone and exclude repeated data.

These two (2) data products offer different retrieval algorithms to generate SSS satellite data. Variations also exist in ancillary inputs, for example SMAP RSS v4 uses GHRSST Level 4 SST data from the Canadian Meteorological Center (CMC) and SMAP JPL v5 uses NOAA Optimum Interpolation SST data. Additional variations include corrections, flags, filters, masks as well as approaches to error and uncertainty estimation. Both products incur errors due to land contamination which each algorithm corrects differently, these corrections will be discussed in the following subsections.

\subsubsection{JPL SSS algorithm}

The SMAP brightness temperature $\left(\mathrm{T}_{\mathrm{B}}\right)$ salinity processing algorithm draws on heritage from the NSCAT, QuikSCAT, RapidScat, and Aquarius projects as well as L-band Geophysical Model Functions (GMFs) developed for the Combined Active / Passive (CAP) Aquarius products produced at the Jet Propulsion Laboratory (JPL) [23].

Tв calibration in the level 1B algorithm has been adjusted in version 5.0 of the SMAP. Numerous Level 1B algorithms were added in the version 3 processing of SMAP inclusive of land correction.

Land energy received as the main lobe of the SMAP antenna is above water created a significant bias on the retrieved Sea Surface Salinity (SSS). Biases as large as -1 psu were observed. A lookup table (LUT) was introduced to correct for land contamination. LUT of land fraction was developed as a function of latitude, longitude and antenna azimuth angle using a repeat cycle of 8-days of SMAP explicitly integrating over the antenna pattern. A "land-near" climatology map was also generated; this climatology represents the expected $\mathrm{T}_{\mathrm{B}}$ of land that contributes to the observation. Using the LUT and climatology of nearby land, the corrected $\mathrm{T}_{в}$ is calculated:

$$
T_{l c}=\frac{T_{o b s}-f_{\text {land }} T_{l, \text { near }}}{1-f_{\text {land }}}
$$

where $T_{l c}$ is the corrected $\mathrm{T}_{\mathrm{B}}, T_{o b s}$ is the observed $\mathrm{T}_{\mathrm{B}}, f_{\text {land }}$ is the land fraction from the LUT, and $T_{l, \text { near }}$ is the near-land Tв. Fore et. al [23] describes in detail the calculated corrections. The JPL sea surface salinity (SSS) product has shown good accuracy in validations carried out by other studies [24-26]. Tang [24], validated the SMAP JPL SSS product, using in-situ data obtained from Argo floats, moored buoys, and TSG. The results revealed an accuracy of 0.2 psu for the zonal band between $40^{\circ} \mathrm{N}$ and $40^{\circ} \mathrm{S}$. Additionally, SMAP JPL replicated significant salinity differences observed by buoys moored in the Tropics for periods less than a month. This was reflected in the RMS difference of $0.26 \mathrm{psu}$ weekly and $0.22 \mathrm{psu}$ monthly. On a global scale, areas such as the high latitudes $\left(>40^{\circ}\right.$ polewards), West African coast, and South American coast prove somewhat challenging for the satellites. The cold temperatures of the water in the high latitudes desensitized the L-band radiometer. Coastal areas were either under-sampled by the Argo floats or experienced land contamination. Fournier [26] also observed the issue while validating six products from three satellite missions (Soil Moisture Ocean Salinity (SMOS), Aquarius, and SMAP) using in-situ data from expendable bathythermographs (XBT), CTDs (Conductivity, Temperature, and Depth sensors), bottles, drifting buoys, and TSGs. The results 
revealed that areas in the Arctic with high sea ice concentration did not reproduce observed TSG transects very well. An additional investigation by Fournier [26] highlighted the inverse relationship between temperature and the RMS difference between SMAP JPL and observed data.

While Fournier [26] and Tang [24] validated the JPL product in geographic space, Bingham [25] validated the SMAP JPL product in terms of seasonality. In this experiment, a generic harmonic analysis was performed, generating annual and semi-annual harmonic fits for all mooring datasets and for both the satellite and gridded products at the nearest point to the moorings. Amplitudes and phases for JPL matched well with those from the moorings. RMS difference for the signal strength between the moorings and SMAP JPL product was $0.074 \pm 0.003$ psu. Finally, in the case of the phase comparison between moorings and JPL the observed RMS difference was $1.27 \pm 0.04$ psu.

\subsubsection{RSS SSS algorithm}

Version 4.0 of SMAP SSS produced operationally by Remote Sensing Systems (RSS) [27] also contains updates for the side lobe correction to mitigate land intrusion and land surface emissivity. Salinity retrievals degrade within $500 \mathrm{~km}$ of land since the land is much warmer than the ocean. A correction for this can be derived from simulated Aquarius and SMAP brightness temperatures. This contamination is dealt with at the top of the atmosphere (TOA), the error is given as:

$$
\Delta_{T O A, B}=\hat{T}_{T O A, B}-\bar{T}_{T O A, B, m l}
$$

where $\hat{T}_{T O A, B}$ is the simulated value of the actually observed signal and $\bar{T}_{T O A, B, m l}$ - true TOA $T_{B}$ coming from the antenna main beam. Using the simulated SMAP $T_{B}$, a table of the $\triangle T O A, B$ is computed. The spatial resolution of the land tables has been increased to $0.125^{\circ}$ in Version 4.0 .

Since SMAP performs a full $360^{\circ}$ scan, the sidelobe correction needs to be derived for a series of different scan positions. Land surface emissivity is an important aspect of correcting the side lobe error. Version 4 corrects for land surface emissivity using a yearly climatology of SMAP $\mathrm{T}_{\mathrm{B}}$ over land versus the land surface emission model from previous versions. Emission from the ocean through side lobes must be removed to obtain SMAP land surface Тв. Measured ocean contaminated $T_{в}$ is given by:

$$
T_{B, \text { meas }}=\left(1-g_{\text {ocean }}\right) T_{B, \text { land }}+g_{\text {ocean }} T_{B, \text { ocean }}
$$

where $g_{\text {ocean }}$ is the gain-weighted ocean fraction in the cell over land $g_{\text {ocean }}=\left(1-g_{\text {land }}\right)$ , $T_{B, \text { meas }}$ is the measured ocean contaminated $\mathrm{T}_{B}, T_{B, \text { land }}$ is the brightness temperature for the land and $T_{B, \text { ocean }}$ is the brightness temperature for the ocean.

With the corrections made in version 4, SSS retrievals can be done within $30-40 \mathrm{~km}$ from land. The standard product of the SMAP Version 4 release is the smoothed product with a spatial resolution of approximately $70 \mathrm{~km}$. The SSS variable $(70 \mathrm{~km})$ is best used as it is significantly less noisy than the $40 \mathrm{~km}$ data.

Like the SMAP JPL product, the SMAP RSS product has been validated extensively. Bao [11] investigated the accuracy of three level 3 salinity products (SMOS from the Barcelona Expert Center, Aquarius v5.0 and SMAP RSS) by comparing them to EN.4.2.1 dataset provided by the Met Office Hadley Centre. The EN.4.2.1 monthly dataset has a resolution of $1^{\circ} \times 1^{\circ}$ and is created using a combination of instruments including: Argo floats, CTDs, gliders, bottles and drifting buoys. It was observed that SMAP RSS was positively biased in the tropics. However, the bias changes to negative moving from the tropics to the subtropics followed by a steady increase moving to the polar region [11]. A closer investigation of the tropics, excluding the data along the coast, revealed that SMAP SSS values closely reflected the observed in-situ data with a RMS difference of $0.233 \mathrm{psu}$. Akin 
to the SMAP JPL product, the RSS product does not show good performance in high latitudes (where it is colder) and coastal areas where land contamination and Radio Frequency Interference (RFI) becomes an issue [24].

In addition to this study, Qin [7], evaluated the performance of the SMAP RSS SSS product using both Argo floats and moored buoys. The results of the comparison between Argo Floats and the RSS product revealed larger biases and root mean squared error (RMSE) in coastal areas than those observed in the open ocean. The errors observed at the coast were attributed to the SST and RFI on the SSS inversions. Additionally, lower latitude dependent RMSE were observed when there was higher SST, lower wind speeds and weaker precipitation conditions. Similar to the RMSE values, the bias of SMAP RSS was also impacted by the precipitation conditions. In the comparison against moored buoys, low RMSE were observed [7].

Fournier [26] also found that the SMAP RSS SSS product replicated TSG transects very well, despite the sparse nature of the observed data. A comparison of the SSS from the TSG and the SSS from the RSS product resulted in an RMS difference of 1.20 psu. Similar to its SMAP counterpart, RSS also showed better performance in areas with low sea ice concentration [26]. Bingham [25] showed that the RSS product was able to replicate seasonal variability observed in data from moorings. The RMS difference for the comparison of the signal strength between the in-situ measurements and remote sensing was $0.070 \pm 0.003 \mathrm{psu}$, while in the case of the phase comparison, a value of $1.30 \pm 0.04$ psu was observed. Similar to Bingham [25], Fournier [28] analyzed the performance of two satellite SSS products (SMOS produced by LOCEAN/IPSL and SMAP RSS) and two in-situ based gridded salinity products (Scripps Institute of Oceanography (SIO) and Japan Agency for Marine-Earth Science and Technology) at replicating monthly, seasonal and interannual variability in close proximity to ten of the world's major freshwater sources including the Amazon. Both satellite products were able to replicate seasonal and interannual changes in SSS close to these river mouths at a more dependable rate than the in-situ products [28]. Furthermore, close to the Amazon river the SMOS and SMAP RSS SSS products not only captured the full spatial extent of the plume during peak discharge consistently, but also the salinity gradients [28]. Fournier [28] also highlights the fact that smaller rivers such as the Columbia River proved challenging to both satellite products due to issues with RFI.

\subsection{Hybrid Coordinate Ocean Model (HYCOM)}

The HYbrid Coordinate Ocean Model or HYCOM (hycom.org) is used by the U.S. Navy on a daily basis as part of their Global Ocean Forecasting System (GOFS) as well as by the National Oceanic and Atmospheric Administration (NOAA) at the National Centers for Environmental Prediction (NCEP) [29]. HYCOM is an assimilated model which, through the Navy Coupled Ocean Data Assimilation (NCODA) system, incorporates satellite observations as well as Argo float, CTD and XBT measurements to forecast ocean variables such as salinity, currents and temperature among others [29]. Additionally, HYCOM's fine resolution makes it an eddy resolving model which has been found to be quite accurate at describing mesoscale ocean behavior and at simulating fast flowing western boundary currents [30]. These elements have made the model a popular choice for researchers to examine freshwater fluxes and salinity budgets [31] and to validate satellite salinity retrievals [12,32]. Due to the inability for Argo floats (one of the model's main sources of in situ data acquisition) to record measurements at areas close to land, HYCOM may have an issue recognizing freshwater discharge in these locations [32]. Over-predictions of HYCOM salinity in certain areas may also be due to deficiencies in the climatological forcing of the model, specifically in its ability to simulate freshwater fluxes [31,33]. The HYCOM data used in this study is from GOFS 3.1 and experiment 93.0 which has a $0.08^{\circ}$ spatial resolution and a 3-hour temporal resolution. Additional HYCOM data, included by JPL in their satellite dataset, was also used in this study.

\subsection{Research Vessel In Situ Measurements}


In situ data from multiple sources (moored buoys, Argo floats, TSGs etc.) are commonly used to validate satellite salinity data [26,34,35]. During the EUREC ${ }^{4} \mathrm{~A}-$ OA/ATOMIC campaign TSGs operated on the three (3) research vessels continuously, recording seawater temperature and conductivity through the intake system of the ships. Onboard the Research Vessel (R/V) L'Atalante (from which data was used for the study) the sensor used was the SEACAT TSG SBE38, with an intake depth of approximately $5 \mathrm{~m}$ deep and a sampling interval of 30 seconds [36]. Calibration of the TSG was carried out by comparing daily samples against the onboard salinometer. Preliminary results onboard during the cruise show the TSG having positive correlation with satellite data and were used alongside the satellite data to identify sampling regions [36]. The CTD system onboard operated at half capacity, only using 14 of the available 28 Niskin bottles along with the Seabird 911+ probe and many other sensors attached to the CTD frame [36]. Through the SBE Seasave software, acquisition, visualization and preprocessing of the CTD data were carried out onboard, allowing for pre-calibration [36]. Salinity samples were analyzed onboard via the onboard salinometer to adjust the salinity profiles.

\subsection{Collocation methodology}

Both 8-day average and orbital RSS and JPL SMAP salinity datasets were collocated with saildrone observations. The 8-day average SMAP data were collocated with the saildrone data using Xarray's interp method for multidimensional interpolation of variables [37]. The orbital SMAP data were collocated with the saildrone data using the Pyresample kd-tree resample_nearest method and SciPy spatial kd-tree method for quick nearestneighbor lookup $[38,39]$. The HYCOM data is included in the SMAP products.

Saildrone data is sampled at 1-min intervals, so many observations will match with the same SMAP retrievals. For both the orbital and 8-day collocation datasets, all saildrone data that matched with a unique SMAP observation were averaged to a single saildrone observation, providing a single collocation matchup.

\section{Results}

\subsection{Accuracy of Saildrone observations}

The accuracy of salinity observations by each of the three saildrones (SD1026, SD1060 and SD 1061) deployed was assessed using duplicate salinity sensors on board each vehicle. Saildrone carries two salinity instruments, the RBR and the Sea-Bird (SBE37) which make measurements at one minute intervals. The salinity data from both instruments are in good agreement except for a small calibration offset. It was recommended by Saildrone, Inc. that the SBE37 data is preferred for salinity measurements (per comm.). Salinity observations from the 1026 saildrone vehicle were mainly used for comparison with satellite and model measurements as this was the only vehicle which made measurements throughout the fresh tongue. Table 1 provides statistical analysis for the duplicate sensors, mean difference, standard deviation difference (STD) and root mean squared error (RSME).

Table 1. Mean difference, standard deviation difference (STD) and root mean squared error (RMSE) between the saildrone SBE and RBR instruments for salinity.

\begin{tabular}{|c|c|c|c|c|}
\hline \multirow[t]{2}{*}{ Vehicle } & \multicolumn{3}{|c|}{$\begin{array}{l}\text { SBE37 - RBR } \\
\text { Salinity (psu) }\end{array}$} & \multirow[b]{2}{*}{ Number } \\
\hline & Mean & STD & RMSE & \\
\hline 1026 & 0.052 & 0.002 & 0.052 & 66240 \\
\hline 1060 & 0.057 & 0.002 & 0.058 & 66240 \\
\hline 1061 & 0.059 & 0.0004 & 0.061 & 66240 \\
\hline
\end{tabular}


Table 1 shows comparisons between the two sensors on each vehicle. There is a consistent small offset ( $0.06 \mathrm{psu}$ ) between the SBE and RBR that is attributed to a constant calibration offset. The standard deviations are $0.01 \mathrm{psu}$, indicating that variability is consistently observed by both sensors. These results confirm the accuracy of the saildrone highlighting that the saildrone is a good tool to validate conventional remote sensing techniques in tropical coastal regions. While this paper focuses on the validation of SMAP salinity datasets using saildrone salinity observations, the paper will also seek to understand the covariability between SSS and SST.

\subsection{Comparison to satellite and model salinity}

The saildrone vehicles were deployed off the south coast of Barbados on the 15 January through 2 March for the EUREC ${ }^{4} \mathrm{~A}-\mathrm{OA} / \mathrm{ATOMIC}$ campaign to understand the interaction over mesoscale ocean eddies. Operating largely between $7^{\circ} \mathrm{N}-13^{\circ} \mathrm{N}$ and $48^{\circ} \mathrm{E}-$ $60^{\circ} \mathrm{E}$, the saildrone vehicles $(1026,1060$ and 1061) embarked on their campaign, encountering eddies on 15 and 22 January and 21 February, sampling the air-sea interactions with their wide array of instruments [40]. Over the month of February, the saildrones met with the R/Vs Ronald H. Brown (2 February) and L'Atalante (5 February) for collocated sampling as well as sampling the area under the research aircraft HALO (10 February). During the month of February, a fresh tongue from the Amazon River advected off the coast of South America into the southern Atlantic Ocean. This event was sampled directly by the 1026 saildrone on 16-19 February. The variability of these events can be seen in Figure 2, depicting salinity and temperature over the entire cruise of the 1026 saildrone along with the collocated SMAP products (JPL \& RSS).

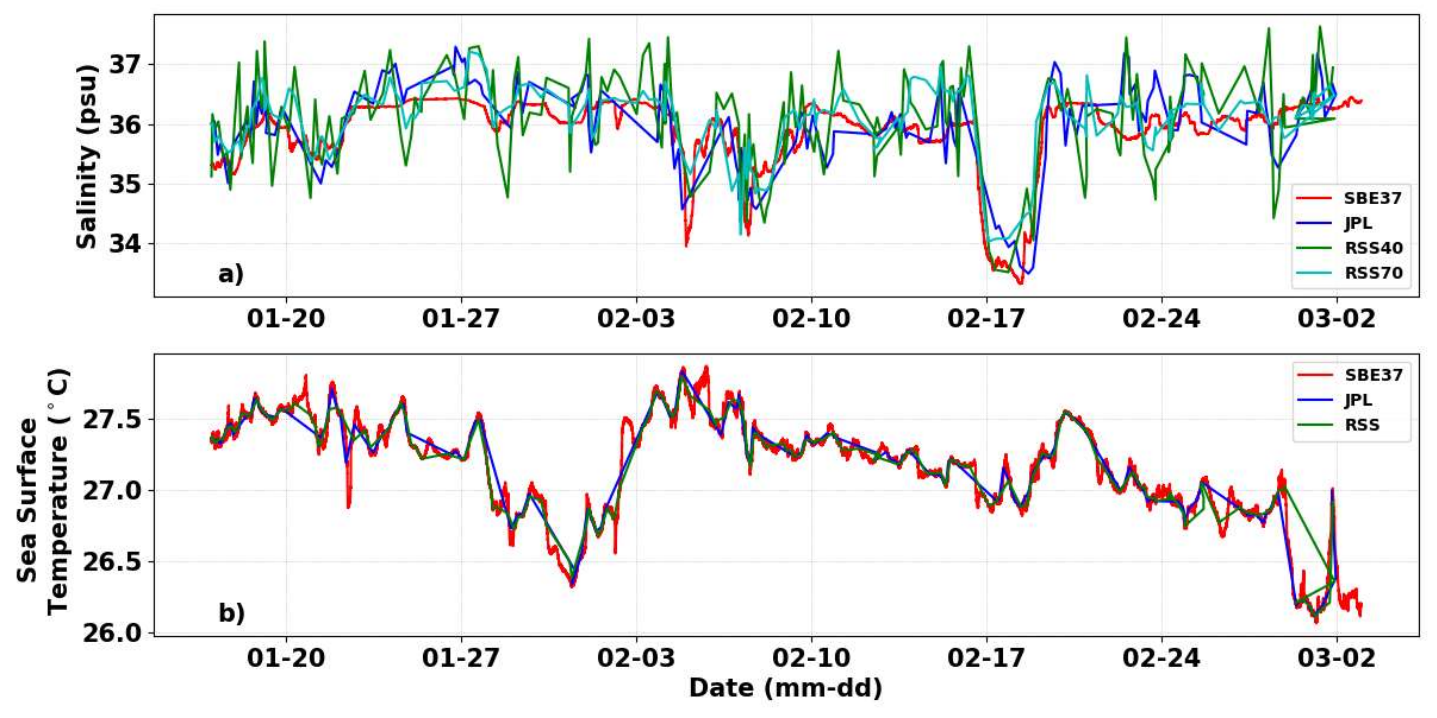

Figure 2. a) Salinity time series and b) SST time series from SBE37, JPL, RSS40 and RSS70.

To examine the consistency among SSS products a time series of SSS and SST was produced for the duration of the cruise (Figure 2). SSS modulates vertical mixing and SST [41]. The Barrier layer (BL) produced as a result of the freshwater influx from the Amazon Orinoco river system may affect biases in SST by affecting vertical mixing and entrainment of cooler water into the ocean mixed layer (OML) [42]. This time series will seek to understand the co-variability of SSS and SST which is critical to validating the performance of the saildrone in the observation of SSS and SST.

Orbital data from the SMAP JPL and RSS were able to capture the main features detected by the saildrone including cold tongues from 27 January - 3 February and another detected from 29 February - 3 March 2020. Data from the orbital 8-day mean SMAP JPL and SMAP RSS captured the cold tongues but were unable to capture the sub mesoscale 
variability as detected by the saildrone, the differences in the data sets are likely due to measurement depth. SSS from the saildrone showed 3 fresh tongues during the 45-day cruise. A 1.5 psu fall in salinity on 5 February, a 1 psu decline on 7 February and the most significant fresh tongue had a decline of 2 psu and occurred from 16-19 February (discussed in section 3.4). All three satellite datasets detected the fresh plumes but failed to accurately measure the salinity and showed higher salinity values as compared to the saildrone. The JPL data also had a temporal delay as compared to the saildrone and the remaining datasets when showing each fresh tongue. Saildrone and remotely sensed data were in general agreement however there were clear biases in the satellite datasets. RSS40 was very noisy which showed clearly in the temporal evolution of the data. SSS data shows larger discrepancies versus the saildrone when compared to the SST data. Statistics were calculated along the entire saildrone track for the duration of the cruise, Table 2 provides the standard deviation difference (STD), and the mean difference for JPL, RSS40, RSS70 with respect to saildrone - remotely sensed SSS as well as HYCOM with respect to saildrone - modeled SSS.

Table 2 shows the mean difference and STD between the various measurements. HYCOM has the second highest STD value which is most likely due to the inability of the model to detect the fresh tongue, thus over-estimating salinity variables for the fresh tongue location (see section 3.3). The RSS40 dataset has the highest STD values overall which correlates with the high quantity of noise present in that dataset. The other differences in STD values will be further discussed in Section 4.

Table 2. Mean difference and STD for saildrone minus satellite observations collocated, repeat observations removed. The averaged salinity saildrone values correspond with the averaged 8-day JPL and RSS products and the 3-hour HYCOM product which was interpolated to the satellite times and locations. The orbital salinity values are each collocated with satellite observations but may have a spatial mismatch.

\begin{tabular}{ccccccc}
\hline \multirow{2}{*}{ Product } & \multirow{2}{*}{ Averaged Salinity (psu) } & \multirow{2}{*}{ Number } & \multicolumn{2}{c}{ Orbital } & \multirow{2}{*}{ Salinity (psu) } & \multirow{2}{*}{ Number } \\
\cline { 5 - 7 } & Mean & STD & & Mean & STD & \\
\hline JPL & -0.166 & 0.241 & 208 & -0.113 & 0.460 & 160 \\
RSS70 & -0.273 & 0.270 & 208 & -0.187 & 0.398 & 160 \\
RSS40 & -0.279 & 0.323 & 208 & -0.188 & 0.658 & 160 \\
HYCOM & -0.127 & 0.520 & 208 & -0.105 & 0.522 & 160 \\
\hline
\end{tabular}

In terms of mean difference, JPL has the smallest mean difference values of the satellites. All mean difference measurements were negative which suggests that the satellite and model datasets as a whole tended to under-estimating rather than over-estimating salinity as compared to the saildrone data.

Figure 3 shows the salinity differences between the various measurements and the saildrone. In Figure 3a the RSS70 salinity difference vs salinity points appear to have the strongest relationship out of the 4 measurements. These points are the most clustered around 0 which suggests that the majority of RSS70 measurements were quite similar to the saildrone observations. The JPL points in Figure $3 \mathrm{~b}$ are a bit more spread out which suggests that JPL may have been slightly less precise in its measurements than the RSS70. The points for RSS40 in Figure 3c were the most spread out which correlates with the high noise content of the data that was observed in Figure 2 and shown in the orbital salinity STD value in Table 2. In Figure 3d, HYCOM salinity difference vs salinity values appear to have a fairly strong positive and linear relationship. HYCOM seems to improve in the accuracy of its observations as salinity increases, as the points with the largest difference values were also the points with the lowest salinity values. This corresponds with what is observed in Figure 4, Figure 5 and Figure 6, where HYCOM fails to model the fresh tongue. 

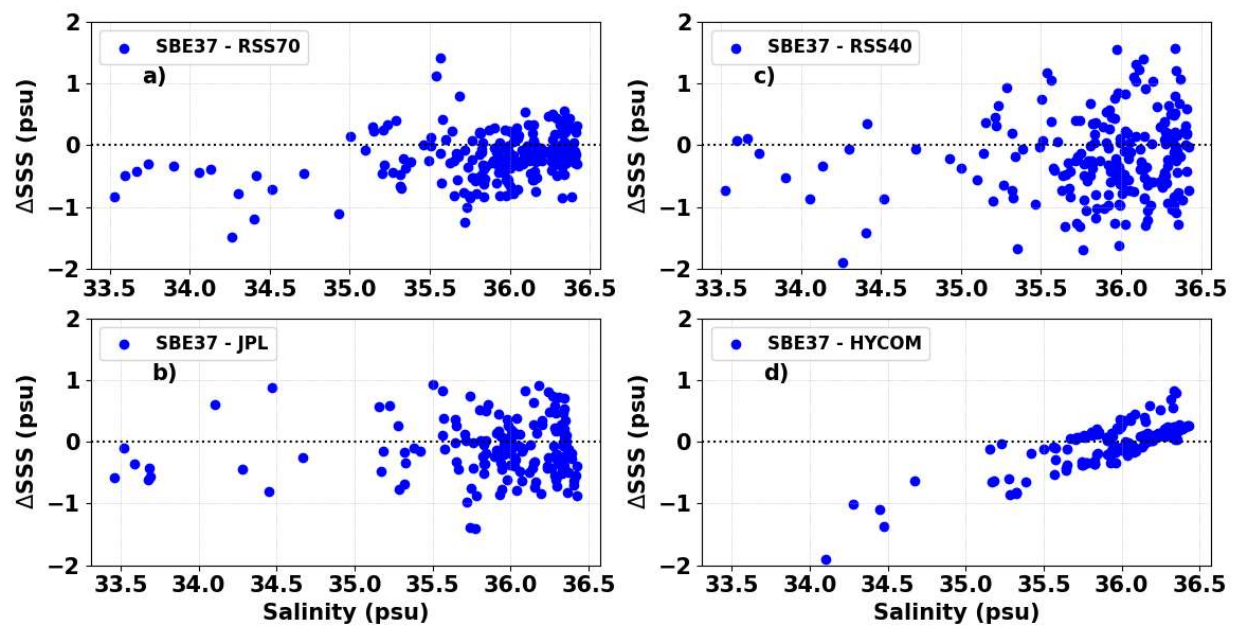

Figure 3: Sea surface salinity difference vs sea surface salinity between a) RSS70, b) JPL and c) RSS40, (orbital no repeat data) and d) HYCOM and the saildrone instrument SBE37 as recorded by saildrone 1026.

\subsection{Spatial Visualization of Fresh Tongue by SMAP products}

Figure 4 shows the spatial distribution of satellite salinity from the different SMAP salinity algorithms A) RSS70, B) RSS40, C) JPL and D) JPL HYCOM along with the saildrone measured salinity for the entire 45-day cruise. The SMAP data in Figure 4 shows less variability than the saildrone measurements, due partly to differences in spatial resolution, but also temporal sampling differences. The JPL product is smoothly varying with some potentially erroneous values in several pixels directly adjacent to South America, but these values could also potentially reflect real coastal variability. The RSS product masks regions near land, and generally matches the JPL retrievals while also appearing to be slightly saltier. The RSS40 salinity clearly has large biases near land that aren't present in the JPL product as well as additional noise, without any clear indication of improved spatial resolution.

Figure 4 shows the 8-day average of the duration of the fresh tongue encountered 1619 February 2020 by the saildrone vehicle. All versions of the SMAP satellite observations identified the fresh tongue, but recorded slightly saltier waters across the fresh tongue when compared with the measurements of the saildrone, measuring a 33.33 psu minimum (2020-02-18 08:59:00) in contrast to the $33.49 \mathrm{psu}, 34.03 \mathrm{psu}$ and $33.52 \mathrm{psu}$ of the JPL, RSS70 and RSS40 respectively. The HYCOM completely misses the fresh tongue event in its prediction as seen in the figure.

Given the absence of the fresh tongue in the HYCOM output in Figure 4, the HYCOM output was investigated to see how the model estimated the event over the month of February. This time frame was abstract but it could give an idea of how well the model performed given the varying lifecycle of the event. The progression of the fresh tongue is clearly seen within the JPL satellite imagery Figure 5, as it makes its way from the Amazon River outlet into the lower Atlantic Basin moving towards the island of Trinidad at the end of the month. In contrast, the JPL HYCOM variable output shows little variation at the mouth of the Amazon River with slightly fresher waters being estimated off of Trinidad by the end of the month with no connection between the outlet and the occurring freshness off Trinidad. 

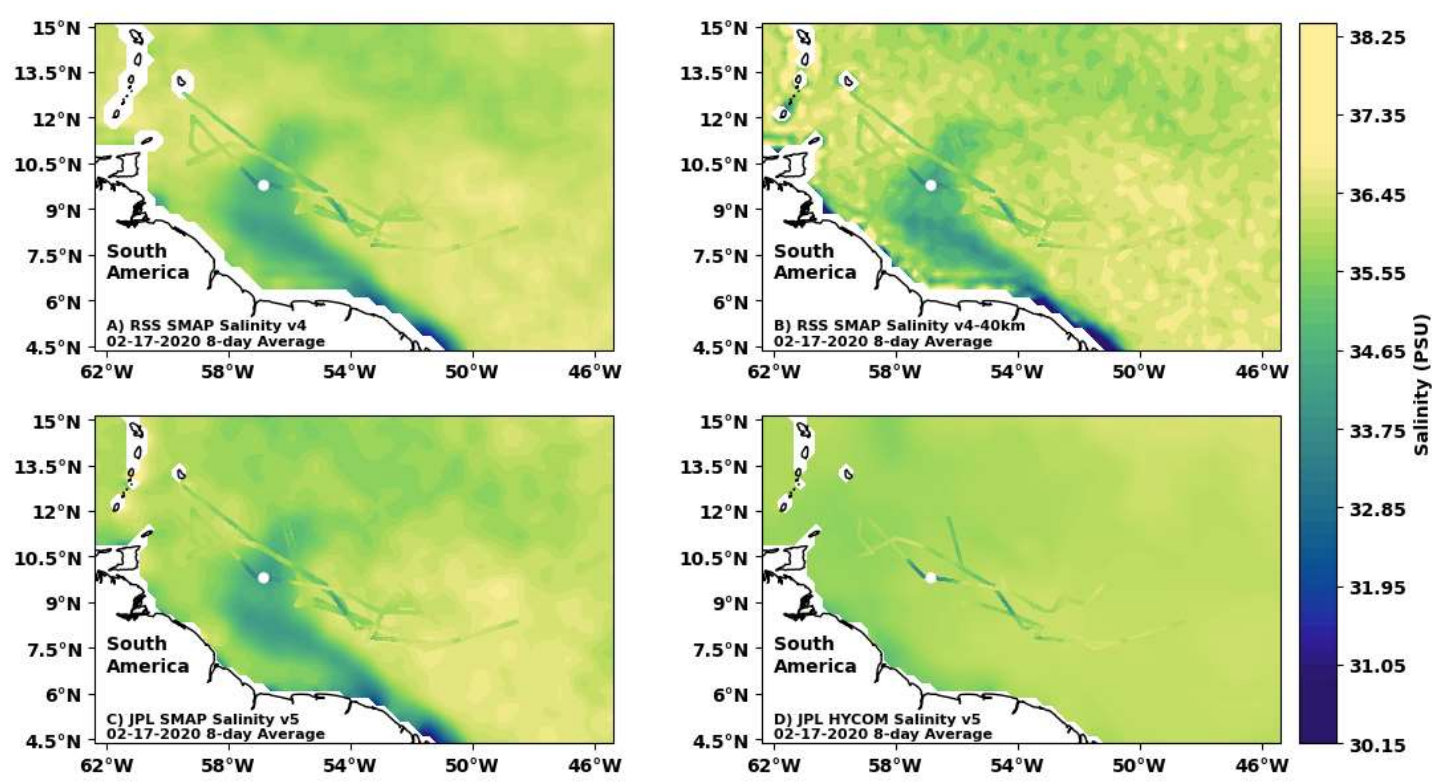

Figure 4: A) Map of RSS70, B) RSS40, C) JPL and D) JPL HYCOM salinity for 8-day average centered on 17 February 2020 shown behind the three saildrone vehicles SBE37 salinity data. On 18 February 2020 the saildrone was crossing the fresh tongue, the vehicle position indicated by white dot.

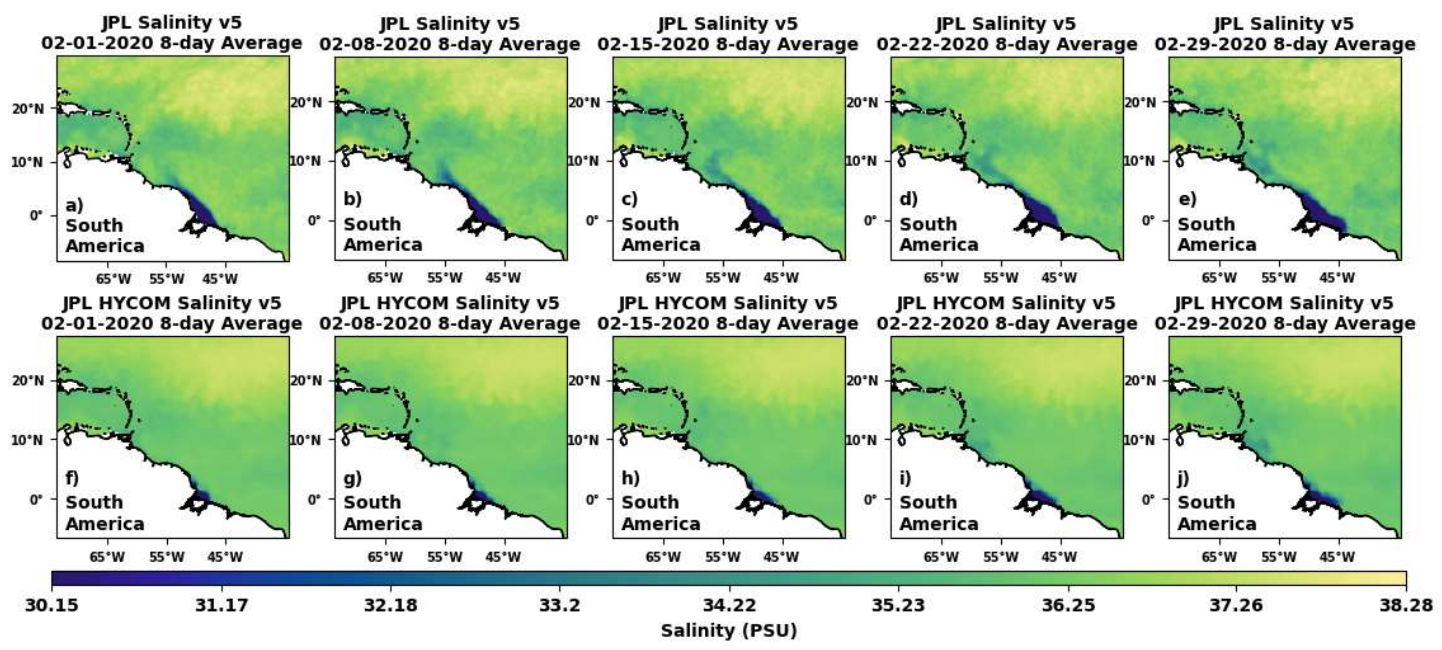

Figure 5: JPL Salinity of the month of February (a-e). JPL HYCOM Salinity of the month of February (f - j).

\subsection{Investigation of Fresh Tongue}

In this subsection we intend to investigate the air sea conditions of the fresh tongue sampled south east of Barbados by both the saildrone and R/V L'Atalante. According to Reverdin et. al. [43], this fresh tongue originated from a plume off the coast of French Guiana. Reverdin et. al. [43] also highlights that the fresh tongue would have been transported to this area by mesoscale eddies as well as the Ekman Transport. This unique feature was first observed in Figure 2 and upon closer inspection it was revealed that the feature was underestimated by both SMAP products as well as HYCOM. The data from both vessels provides an opportunity for us to better understand this feature, which will help with improving both the satellite and modelled products.

\subsection{Investigation of Fresh Tongue via saildrone}


Figure 6 highlights the time series of both the air and sea variables captured by the saildrones and the SMAP JPL and RSS products as the saildrones journeyed through the fresh tongue. Figure 6a puts the sea surface salinity into focus by comparing the data observed by the saildrones with data from RSS40 and RSS70, JPL and HYCOM. A closer observation of the Figure reveals that all satellite products were able to resolve the SSS observed in the fresh tongue, albeit not as detailed as the data from the saildrone. Despite not being as intricate as the SSS from the saildrone, the RSS40 was the only satellite product to capture the small surge observed in salinity at approximately midday on 18 February 2020. Contrary to the satellite products, the fresh tongue went completely unnoticed in the HYCOM model.
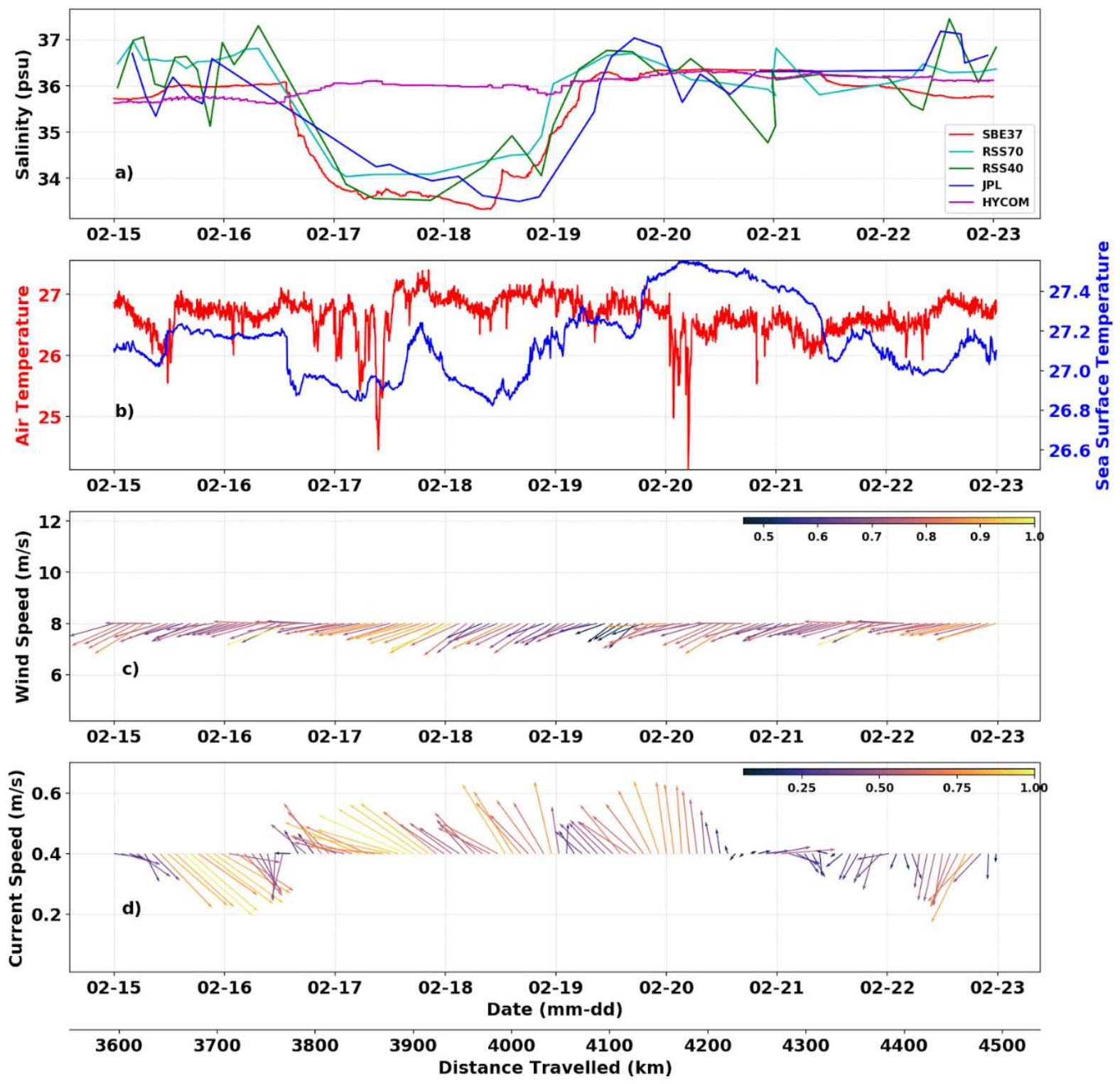

Figure 6: Time series of a) the salinity measured by the SBE37 sensor onboard the saildrone compared with that of HYCOM, RSS70, RSS40 and JPL satellite salinity products b) the air and sea temperature c) the wind speeds and direction d) current speed and direction measured while saildrone 1026 crossed the fresh tongue south east of Barbados from 16 Feb 202012 UTC to 19 Feb 20209 UTC. 
Upon entering the fresh tongue, the SST fell by approximately $0.3^{\circ} \mathrm{C}$ and the air temperature rose by the same approximate value (Figure $6 \mathrm{~b}$ ). A similar heat exchange phenomenon occurred on 17 February 2020, however on this occasion the drop in air temperature preceded the rise in SST. Furthermore, the exchange seemed to take place at a quicker rate on the first occurrence than on the second. This may be due to the difference in specific heat capacity of both fluids.

The variability observed for wind direction inside the fresh tongue was infinitesimal, with the majority of the winds originating from either a north north-easterly direction or a north easterly direction (Figure 6c). However, the magnitude of these winds showed more fluctuation ranging from $4-12 \mathrm{~ms}^{-1}$. The direction of the observed currents showed more variation than the winds but the magnitude of these currents were only about $10 \%$ as strong as the winds observed.

\subsubsection{Investigation of fresh tongue via $\mathrm{R} / \mathrm{V}$ L'Atalante}

The EUREC ${ }^{4} \mathrm{~A}-\mathrm{OA} / \mathrm{ATOMIC}$ campaign presented the opportunity of multi-platform investigation. Branching out from the saildrone vehicles, four research vessels took part in the campaign efforts, bringing a myriad of instrumentation with them. The R/V Maria S. Merian and L'Atalante sampled the fresh tongue on 2 Feb and 7-8 Feb 2020 respectively. Being closest to the saildrone encounter, data from the L'Atalante encounter was investigated.

During that period, salinity sampling was recorded by the vessel's TSG and 16 CTD casts (Figure 7). The vessel approached the fresh tongue on the $7 \mathrm{Feb}$ where 8 CTD casts were carried out between 1 AM and 2 PM and exited the fresh tongue on the 8 February, on which 8 more casts were done between $4 \mathrm{AM}$ and $2 \mathrm{PM}$ (Figure 7a-b). Only 7 casts are shown on the TSG time series plot Figure $7 \mathrm{~d}$ because the fourth cast started recording at $106 \mathrm{~m}$ depth. No CTD casts were conducted while traversing the tongue. Investigation of the tongue was still able to be monitored via the TSG. Average salinity approaching the fresh tongue was a measured 35.424 psu and an averaged 35.579 psu after leaving the tongue, with a minimum of $34.627 \mathrm{psu}$ across the tongue. The CTD measurements were consistently higher than the TSG counterparts, with an average difference of 0.0357 psu.

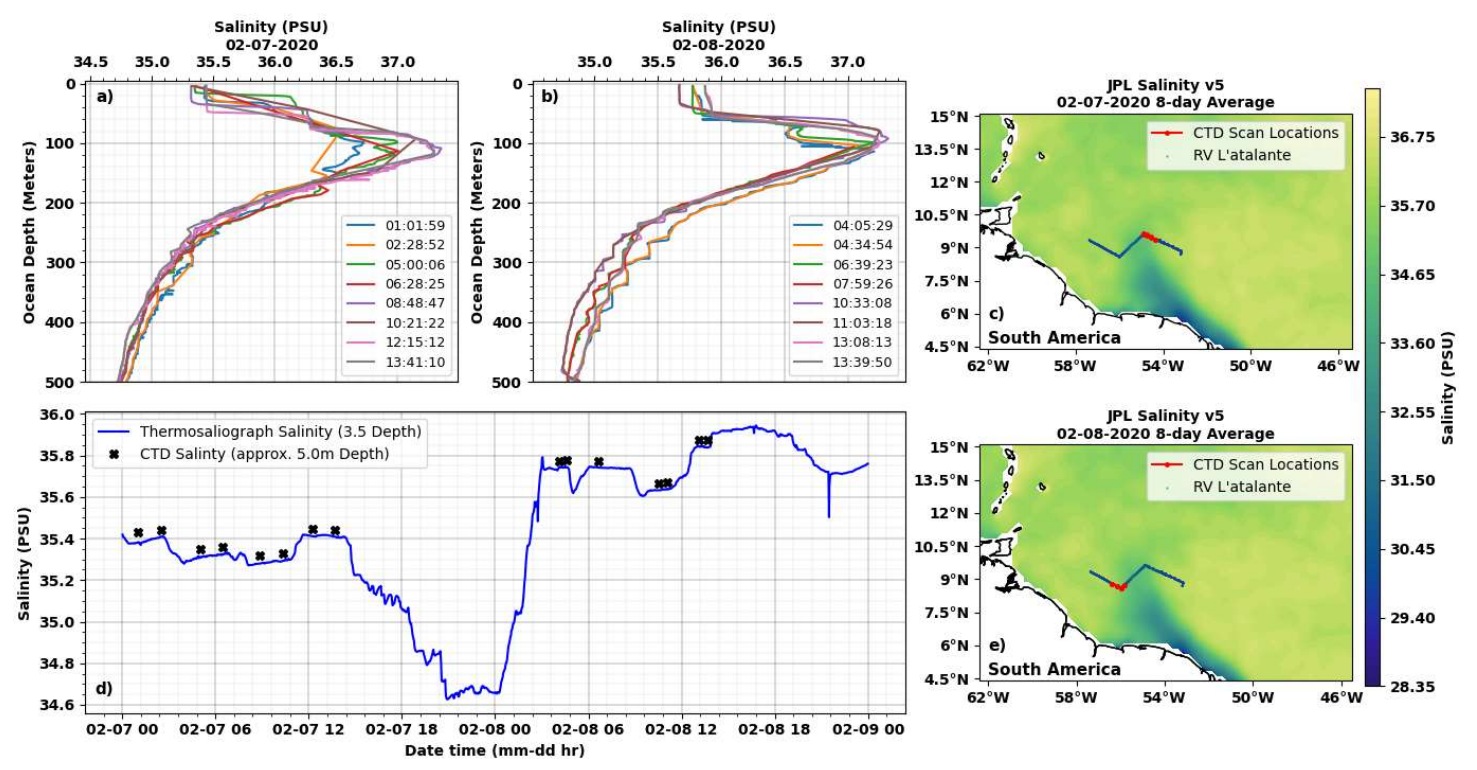

Figure 7. A) CTD Salinity Profiles recorded 7 Feb 2020 by the Research Vessel L'Atalante, B) CTD Salinity Profiles recorded 8 Feb 2020 by the Research Vessel L'Atalante, C) JPL Salinity v5 SMAP 8-day average recorded 7 Feb 2020, D) Thermosalinograph time series with CTD upper most scans and E) JPL Salinity v5 SMAP 8-day average recorded 8 Feb 2020. 


\section{Discussion}

The EUREC ${ }^{4} \mathrm{~A}-\mathrm{OA} / \mathrm{ATOMIC}$ campaign highlighted not only the accuracy of the data provided by the saildrones but also the flexibility of equipment. Saildrones were directed to areas of significant interest in the Boulevard des Tourbillons and were able to provide exceptional spatial and temporal data. The high quality of the data was reflected in the low RMSE values produced during the comparison of duplicate sensors on each saildrone (Table 1). The saildrones also acted as the perfect complement to the three larger research vessels (R/V L'Atalante, R/V Ronald H. Brown and R/V Maria S. Merian) since ships start observations about 5-7 $\mathrm{m}$ above and below the surface of the ocean [36]. On a more somber note, a few months after the campaign, the COVID-19 pandemic forced the world into a complete shutdown, putting research campaigns on pause. A situation of this magnitude highlights the importance of autonomous vehicles like saildrones. The aforementioned benefits of the saildrones made it an ideal data source to validate the satellite salinity and model salinity products.

In this study, salinity values from four different platforms were compared against the saildrone salinity observations. Out of these four, RSS70 appeared to be the platform which most closely matched the salinity values recorded by saildrone, according to its STD difference value of $0.398 \mathrm{psu}$, then followed by JPL ( $0.460 \mathrm{psu})$, then HYCOM (0.522 $\mathrm{psu}$ ) and finally RSS40 ( $0.658 \mathrm{psu})$. In all cases, each of the platforms tended to underestimate salinity values as the majority of the measurements were more fresh than those recorded by the saildrone, this is expected since satellite derived SSS have lower spatial resolutions compared to the saildrone. The JPL product performed well with the second best STD value of $0.46 \mathrm{psu}$. This is expected since it has an effective spatial resolution of $60 \mathrm{~km}$, higher than that of the RSS40 but less than the RSS70. Of note was the temporal offset displayed by the JPL dataset within the fresh tongues observed (Figures 2 and 6) which may have been as a result of a time difference between the satellite and the saildrone. The RSS40 data was the noisiest out of all four platforms and had an STD difference value that was almost twice as large as its RSS70 counterpart, this noise is most likely due to land contamination and reduced spatial smoothing. This suggests that for most applications the RSS70 data should definitely be preferred over RSS40, these results are in agreement with previous validation papers $[15,35]$.

The most prominent feature to occur over the course of the saildrone cruise was the salinity minimum experienced during the 16-19 Feb 2020. This sharp drop in salinity, 1.19 psu in $13 \mathrm{~m}$ and consequently reaching its minimum of $33.33 \mathrm{psu}(-2.74 \mathrm{psu})$ approximately $200 \mathrm{~m}$ later, was spatially visualized in Figure 4 to examine how well the SMAP products could tell the story of what the saildrone 1026 was experiencing. The fresh tongue was adequately displayed by the JPL and RSS products, showcasing the products' ability to respond to advections of freshwater. Unexpectedly, the RSS40 performs the best inside the fresh tongue, despite its noisy nature. It was the only product that was able to depict the sharpest rise in salinity inside the fresh tongue which is presumably because it has the highest spatial resolution of the satellite datasets. Another alarming observation is the fact that the JPL HYCOM SSS variable does not record the salinity minimum at all. As seen in Figures 5 and $6 \mathrm{a}$, there was no identification (in the case of Figure $5 \mathrm{f}$ and Figure 5j) or variation (in the case of Figure 6) in the HYCOM salinity. Coles et al. [44] defined a rule of thumb of the 35 isohaline to identify the Amazon plume within their model output. Encapsulating our study area in their domain, salinity within the plume remained under 35 psu as it moved into the open ocean off the coasts of South America. This is not consistent with the JPL HYCOM SSS variable as Figure 6 shows the HYCOM variable consistently above $35 \mathrm{psu}$.

HYCOM overall appeared to have the least noisy dataset and did have several measurements in good agreement with saildrone, but it neglected to model the fresh tongue. This is most likely due to the model's deficiencies in climatological forcing. Thus, HYCOM may be useful for measuring large scale salinity conditions but is not as reliable for portraying mesoscale or submesoscale salinity irregularities. 


\section{Conclusions}

During the EUREC ${ }^{4} \mathrm{~A}-\mathrm{OA} / \mathrm{ATOMIC}$ campaign, saildrones and research vessels were deployed in the North Equatorial Current and the Boulevard des Tourbillons in order to investigate mesoscale eddies and submesoscale fronts and their role in ocean-atmosphere interactions. In this study, saildrone salinity observations recorded during the campaign were compared with four different SSS products SMAP JPL, SMAP RSS $40 \mathrm{~km}$, SMAP RSS $70 \mathrm{~km}$ and HYCOM, with the aim of highlighting the strengths and weaknesses of each product. This study represents the first validation of SMAP satellite derived SSS using the saildrone in the river influenced Western Tropical Atlantic, and this information can allow researchers to make informed decisions regarding the most ideal product for their application as well as highlight issues to algorithm developers. Overall, it was found that SMAP RSS $70 \mathrm{~km}$ outperformed its counterparts in areas with no submesoscale irregularities. However, RSS $40 \mathrm{~km}$ was better at identifying small irregularities in salinity such as a fresh tongue, with HYCOM being on the opposite spectrum, failing to identify the tongue. Akin to the RSS $70 \mathrm{~km}$, JPL and HYCOM performed well in areas where the largescale salinity conditions were constant. Finally, the results of this study can aid in the improvement of mesoscale and submesoscale SSS products, which can lead to the refinement of NWP and climate models and therefore to improved weather, ocean and climate forecasts, especially for tropical regions.

Author Contributions: This research paper was conceptualized by Chelle Gentemann. Software was developed by Kashawn Hall, Alton Daley, Shanice Whitehall, Sanola Sandiford and Chelle Gentemann. The validation process was executed by Sanola Sandiford. The formal analysis was done by Kashawn Hall, Alton Daley, Shanice Whitehall, Sanola Sandiford and Chelle Gentemann. Resources were provided by the Caribbean Institute for Meteorology and Hydrology and Fallron Institute and the data was curated by Chelle Gentemann. Writing-original draft preparation was executed by Kashawn Hall, Alton Daley, Shanice Whitehall, Sanola Sandiford and Chelle Gentemann and review and editing included Kashawn Hall, Alton Daley, Shanice Whitehall, Sanola Sandiford and Chelle Gentemann. Data visualization was executed by Kashawn Hall, Alton Daley, Shanice Whitehall, Sanola Sandiford. Figure 2 was created by Shanice Whitehall, Figure 3 was created by Sanola Sandiford, Figure 6 was created by Alton Daley and Figures 4,5 and 7 were created by Kashawn Hall. The project was supervised by Chelle Gentemann.

Funding: This research funding was provided by NASA Physical Oceanography grant \#80NSSC20K0768.

Data Availability Statement: The Saildrone v1 data presented in this study are openly available at https://podaac.jpl.nasa.gov/dataset/SAILDRONE_ATOMIC at 10.5067/SDRON-ATOM0. The HYCOM GOFS 3.1 data presented in this study are openly available at https://www.hycom.org/dataserver/gofs-3pt1/analysis at http://dx.doi.org/10.5670/oceanog.2014.66. The SMAP data presented in the study are openly available at https://podaac.jpl.nasa.gov/datasetlist?search=smap at 10.5067/SMP50-2NOCS and 10.5067/SMP40-2SOCS. The research vessel data are openly available at https://observations.ipsl.fr/aeris/eurec4a/\#/. Software and data needed to reproduce tables and figures are available at https:/github.com/cgentemann/paper_software/tree/master/2020_ATOMIC_Salinity. (Note - we will create a new repository with a DOI and binder link at the end of the review process).

Acknowledgments: The authors would like to acknowledge and thank Dr. David Farrell of the Caribbean Institute for Meteorology and Hydrology for providing the opportunities to participate in the EUREC ${ }^{4} \mathrm{~A}-\mathrm{OA} / \mathrm{ATOMIC}$ campaign and enabling collaborations with Dr. Chelle Gentemann of the Farallon Institute. Sarah Ann Thompson added references and proofread the document. The research vessel data used in this publication was gathered in the EUREC ${ }^{4} \mathrm{~A}$ field campaign and is made available through [insert name of the institute]. EUREC ${ }^{4} \mathrm{~A}$ is funded with support of the European Research Council (ERC), the Max Planck Society (MPG), the German Research Foundation (DFG), the German Meteorological Weather Service (DWD) and the German Aerospace Center (DLR). 
Conflicts of Interest: The authors declare no conflict of interest. The funders had no role in the design of the study; in the collection, analyses, or interpretation of data; in the writing of the manuscript, or in the decision to publish the results.

\section{References}

1. Johns, W.E.; Townsend, T.L.; Fratantoni, D.M.; Wilson, W.D. On the Atlantic Inflow to the Caribbean Sea. Deep Sea Res. Part Oceanogr. Res. Pap. 2002, 49, 211-243, doi:10.1016/S0967-0637(01)00041-3.

2. Stevens, B.; Serikov, I.; Albright, A.L.; Bony, S.; George, G.; Hirsch, L.; Jansen, F.; Kölling, T.; Schulz, H.; Vogel, R.; et al. Why Sometimes Its Simply Sunny (in the Trades). 2021, EGU21-15408.

3. Fratantoni, D.M.; Glickson, D.A. North Brazil Current Ring Generation and Evolution Observed with SeaWiFS. J. Phys. Oceanogr. 2002, 32, 1058-1074, doi:10.1175/1520-0485(2002)032<1058:NBCRGA>2.0.CO;2.

4. EUREC4A EUREC4A-OA.

5. Droghei, R.; Buongiorno Nardelli, B.; Santoleri, R. A New Global Sea Surface Salinity and Density Dataset From Multivariate Observations (1993-2016). Front. Mar. Sci. 2018, 0, doi:10.3389/fmars.2018.00084.

6. Wang, C.; Zhang, L. Multidecadal Ocean Temperature and Salinity Variability in the Tropical North Atlantic: Linking with the AMO, AMOC, and Subtropical Cell. J. Clim. 2013, 26, 6137-6162, doi:10.1175/JCLI-D-12-00721.1.

7. Qin, S.; Wang, H.; Zhu, J.; Wan, L.; Zhang, Y.; Wang, H. Validation and Correction of Sea Surface Salinity Retrieval from SMAP. Acta Oceanol. Sin. 2020, 39, 148-158, doi:10.1007/s13131-020-1533-0.

8. Lagerloef, G.S.E. Introduction to the Special Section: The Role of Surface Salinity on Upper Ocean Dynamics, Air-Sea Interaction and Climate. J. Geophys. Res. Oceans 2002, 107, SRF 1-1-SRF 1-2, doi:10.1029/2002JC001669.

9. Durack, P.J.; Wijffels, S.E.; Matear, R.J. Ocean Salinities Reveal Strong Global Water Cycle Intensification During 1950 to 2000. Science 2012, 336, 455-458, doi:10.1126/science.1212222.

10. Bingham, F.M.; Howden, S.D.; Koblinsky, C.J. Sea Surface Salinity Measurements in the Historical Database. J. Geophys. Res. Oceans 2002, 107, SRF 20-1-SRF 20-10, doi:10.1029/2000JC000767.

11. Bao, S.; Wang, H.; Zhang, R.; Yan, H.; Chen, J. Comparison of Satellite-Derived Sea Surface Salinity Products from SMOS, Aquarius, and SMAP. J. Geophys. Res. Oceans 2019, 124, 1932-1944, doi:10.1029/2019JC014937.

12. Kao, H.-Y.; Lagerloef, G.S.E.; Lee, T.; Melnichenko, O.; Meissner, T.; Hacker, P. Assessment of Aquarius Sea Surface Salinity. Remote Sens. 2018, 10, 1341, doi:10.3390/rs10091341.

13. Vinogradova, N.; Lee, T.; Boutin, J.; Drushka, K.; Fournier, S.; Sabia, R.; Stammer, D.; Bayler, E.; Reul, N.; Gordon, A.; et al. Satellite Salinity Observing System: Recent Discoveries and the Way Forward. Front. Mar. Sci. 2019, 0, doi:10.3389/fmars.2019.00243.

14. Srokosz, M.; Banks, C. Salinity from Space. Weather 2019, 74, 3-8, doi:10.1002/wea.3161.

15. Vazquez-Cuervo, J.; Gomez-Valdes, J.; Bouali, M.; Miranda, L.E.; Van der Stocken, T.; Tang, W.; Gentemann, C. Using Saildrones to Validate Satellite-Derived Sea Surface Salinity and Sea Surface Temperature along the California/Baja Coast. Remote Sens. 2019, 11, 1964, doi:10.3390/rs11171964.

16. Balaguru, K.; Chang, P.; Saravanan, R.; Jang, C.J. The Barrier Layer of the Atlantic Warmpool: Formation Mechanism and Influence on the Mean Climate. Tellus Dyn. Meteorol. Oceanogr. 2012, 64, 18162, doi:10.3402/tellusa.v64i0.18162.

17. Androulidakis, Y.; Kourafalou, V.; Halliwell, G.; Le Hénaff, M.; Kang, H.; Mehari, M.; Atlas, R. Hurricane Interaction with the Upper Ocean in the Amazon-Orinoco Plume Region. Ocean Dyn. 2016, 66, 1559-1588, doi:10.1007/s10236-016-0997-0.

18. Gentemann, C.L.; Scott, J.P.; Mazzini, P.L.F.; Pianca, C.; Akella, S.; Minnett, P.J.; Cornillon, P.; Fox-Kemper, B.; Cetinić, I.; Chin, T.M.; et al. Saildrone: Adaptively Sampling the Marine Environment. Bull. Am. Meteorol. Soc. 2020, 101, E744-E762, doi:10.1175/BAMS-D-19-0015.1.

19. Cokelet, E.D.; Meinig, C.; Lawrence-Slavas, N.; Stabeno, P.J.; Mordy, C.W.; Tabisola, H.M.; Jenkins, R.; Cross, J.N. The Use of Saildrones to Examine Spring Conditions in the Bering Sea. In Proceedings of the OCEANS 2015 - MTS/IEEE Washington; October 2015; pp. 1-7.

20. Zhang, D.; Cronin, M.F.; Meinig, C.; Farrar, J.T.; Jenkins, R.; Peacock, D.; Keene, J.; Sutton, A.; Yang, Q. Comparing Air-Sea Flux Measurements from a New Unmanned Surface Vehicle and Proven Platforms during the SPURS-2 Field Campaign. Oceanography 2019, 32, 122-133.

21. Gilhousen, D.B. A Field Evaluation of NDBC Moored Buoy Winds. J. Atmospheric Ocean. Technol. 1987, 4, 94-104, doi:10.1175/1520-0426(1987)004<0094:AFEONM>2.0.CO;2.

22. Bowen, B. Improved Wind and Turbulence Measurements Using a Low-Cost 3-D Sonic Anemometer at a Low-Wind Site; Lawrence Livermore National Lab. (LLNL), Livermore, CA (United States), 2007;

23. Fore, A.G.; Yueh, S.H.; Tang, W.; Hayashi, A.K. SMAP Salinity and Wind Speed Data User's Guide, Version 5; Jet Propulsion Laboratory, 2020; p. 42;.

24. Tang, W.; Yueh, S.H.; Fore, A.; Neumann, G.; Hayashi, A. Rain Effect on Aquarius L-Band Emissivity and Backscatter Model Functions. 2012, 2012, OS13E-1772.

25. Bingham, F.M.; Fournier, S.; Brodnitz, S.; Ulfsax, K.; Zhang, H. Matchup Characteristics of Sea Surface Salinity Using a HighResolution Ocean Model. 2021. 
26. Fournier, S.; Lee, T.; Tang, W.; Steele, M.; Olmedo, E. Evaluation and Intercomparison of SMOS, Aquarius, and SMAP Sea Surface Salinity Products in the Arctic Ocean. Remote Sens. 2019, 11, 3043, doi:10.3390/rs11243043.

27. Meissner, T.; Wentz, F.J.; Manaster, A.; Lindsley, R.; Grodsky, S.A.; Vazquez, Jorge.; Kao, H.-Y.; Levine, D. NASA/RSS SMAP Salinity: Version 4.0 Validated Release Algorithm Theoretical Basis Document (ATBD); Remote Sensing Systems, 2019;

28. Fournier, S.; Lee, T.; Tang, W.; Steele, M.; Olmedo, E. Evaluation and Intercomparison of SMOS, Aquarius, and SMAP Sea Surface Salinity Products in the Arctic Ocean. 2021, 43, 97.

29. Metzger, E.J.; Smedstad, O.M.; Thoppil, P.G.; Hurlburt, H.E.; Cummings, J.A.; Wallcraft, A.J.; Zamudio, L.; Franklin, D.S.; Posey, P.; Phelps, M.; et al. US Navy Operational Global Ocean and Arctic Ice Prediction Systems. Oceanography 2014, $27,32-43$.

30. Cummings, J.A.; Smedstad, O.M. Ocean Data Impacts in Global HYCOM. J. Atmospheric Ocean. Technol. 2014, 31, 1771-1791, doi:10.1175/JTECH-D-14-00011.1.

31. Wilson, E.A.; Riser, S.C. An Assessment of the Seasonal Salinity Budget for the Upper Bay of Bengal. J. Phys. Oceanogr. 2016, 46, 1361-1376, doi:10.1175/JPO-D-15-0147.1.

32. Meissner, T.; Wentz, F.J.; Le Vine, D.M. The Salinity Retrieval Algorithms for the NASA Aquarius Version 5 and SMAP Version 3 Releases. Remote Sens. 2018, 10, 1121, doi:10.3390/rs10071121.

33. Castellanos, P.; Olmedo, E.; Pelegrí, J.L.; Turiel, A.; Campos, E.J.D. Seasonal Variability of Retroflection Structures and Transports in the Atlantic Ocean as Inferred from Satellite-Derived Salinity Maps. Remote Sens. 2019, 11, 802, doi:10.3390/rs11070802.

34. Tang, W.; Fore, A.; Yueh, S.; Lee, T.; Hayashi, A.; Sanchez-Franks, A.; Martinez, J.; King, B.; Baranowski, D. Validating SMAP SSS with in Situ Measurements. Remote Sens. Environ. 2017, 200, 326-340, doi:10.1016/j.rse.2017.08.021.

35. Menezes, V.V. Statistical Assessment of Sea-Surface Salinity from SMAP: Arabian Sea, Bay of Bengal and a Promising Red Sea Application. Remote Sens. 2020, 12, 447, doi:10.3390/rs12030447.

36. Speich, S.; The Embarked Science Team EUREC4A-OA. Cruise Report. 19 January - 19 February 2020. Vessel : L'ATALANTE. 2021.

37. Hoyer, S.; Hamman, J.; Roos, M.; keewis; Cherian, D.; Fitzgerald, C.; Fujii, K.; Maussion, F.; Hauser, M.; crusaderky; et al. Pydata/Xarray: V0.18.2; Zenodo, 2021;

38. Hoese, D.; Lahtinen, P.; Raspaud, M.; Roberts, W.; Lavergne; Bot, S.; Finkensieper, S.; Dybbroe, A.; Holl, G.; Itkin, M.; et al. Pytroll/Pyresample: Version 1.20.0. 2021, doi:10.5281/zenodo.4900011.

39. Gommers, R.; Virtanen, P.; Burovski, E.; Oliphant, T.E.; Weckesser, W.; Cournapeau, D.; Reddy, T.; alexbrc; Haberland, M.; Peterson, P.; et al. Scipy/Scipy: SciPy 1.7.1; Zenodo, 2021;

40. Gentemann, C.L.; Vazquez, Jorge.; Tang, W. 2020 Atomic Saildrone Cruise Report. 2020, doi:10.5281/zenodo.5201863.

41. Foltz, G.R.; Brandt, P.; Richter, I.; Rodríguez-Fonseca, B.; Hernandez, F.; Dengler, M.; Rodrigues, R.R.; Schmidt, J.O.; Yu, L.; Lefevre, N.; et al. The Tropical Atlantic Observing System. Front. Mar. Sci. 2019, 0, doi:10.3389/fmars.2019.00206.

42. Breugem, W.-P.; Chang, P.; Jang, C.J.; Mignot, J.; Hazeleger, W. Barrier Layers and Tropical Atlantic SST Biases in Coupled GCMs. Tellus Dyn. Meteorol. Oceanogr. 2008, 60, 885-897, doi:10.1111/j.1600-0870.2008.00343.x.

43. Reverdin, G.; Olivier, L.; Foltz, G.R.; Speich, S.; Karstensen, J.; Horstmann, J.; Zhang, D.; Laxenaire, R.; Carton, X.; Branger, H.; et al. Formation and Evolution of a Freshwater Plume in the Northwestern Tropical Atlantic in February 2020. J. Geophys. Res. Oceans 2021, 126, e2020JC016981, doi:10.1029/2020JC016981.

44. Coles, V.J.; Brooks, M.T.; Hopkins, J.; Stukel, M.R.; Yager, P.L.; Hood, R.R. The Pathways and Properties of the Amazon River Plume in the Tropical North Atlantic Ocean. J. Geophys. Res. Oceans 2013, 118, 6894-6913, doi:10.1002/2013JC008981. 